\title{
Spatiotemporal evolution of urban air quality and socioeconomic driving forces in China
}

\author{
LIN Xueqin ${ }^{1}$, "WANG Dai ${ }^{2}$ \\ 1. College of Resources Environment and Tourism, Capital Normal University, Beijing 100048, China; \\ 2. Institute of Geographic Sciences and Natural Resources Research, CAS, Beijing 100101, China
}

\begin{abstract}
Air pollution is a serious problem brought by the rapid urbanization and economic development in China, imposing great challenges and threats to population health and the sustainability of the society. Based on the real-time air quality monitoring data obtained for each Chinese city from 2013 to 2014, the spatiotemporal characteristics of air pollution are analyzed using various exploratory spatial data analysis tools. With spatial econometric models, this paper further quantifies the influences of socioeconomic factors on air quality at both the national and regional scales. The results are as follows: (1) From 2013 to 2014, the percentage of days compliance of urban air quality increased but air pollution deteriorated and the worsening situation in regions with poor air quality became more obvious. (2) Changes of air quality show a clear temporal coupling with regional socioeconomic activities, basically "relatively poor at daytime and relatively good at night". (3) Urban air pollution shows a spatial pattern of "heavy in the east and light in the west, and heavy in the north and light in the south". (4) The overall extent and distribution of regional urban air pollution have clearly different characteristics. The formation and evolution of regional air pollution can be basically induced as "the pollution of key cities is aggravated-pollution of those cities spreadsregional overall pollution is aggravated-the key cities lead in pollution governance-regional pollution joint prevention and control is implemented-regional overall pollution is reduced". (5) At the national level, energy consumption, industrialization and technological progress are the major factors in the worsening of urban air quality, economic development is a significant driver for the improvement of that quality. (6) Influenced by resources, environment and the development stage, the socioeconomic factors had strongly variable impacts on air quality, in both direction and intensity in different regions. Based on the conclusion, the regional differentiation and development idea of the relationship between economic development and environmental changes in China are discussed.
\end{abstract}

Keywords: urban air quality; spatiotemporal variations; socioeconomic driving forces; China

Received: 2016-06-29 Accepted: 2016-08-10

Foundation: Key Program of National Natural Science Foundation of China, No.41430636; Youth Program of the Humanities and Social Science Research of Ministry of Education, No.16YJC790056

Author: Lin Xueqin, PhD, specialized in regional sustainable development. E-mail: lin-xueqin@139.com

*Corresponding author: Wang Dai, PhD, specialized in urban and regional development. E-mail: wangdai@igsnrr.ac.cn 


\section{Introduction}

From 1978 to 2012, China's GDP increased from 364.5 billion to 51.8942 trillion RMB yuan, with an annual growth rate of $9.98 \%$. Its urbanization rate increased from $17.92 \%$ to $52.57 \%$, with an annual growth rate of $0.96 \%$. Economic development and promotion of urbanization has supported the rapid accumulation of material wealth over a short period and substantial improvement of people's life. However, it has also caused severe ecological environment problems in many regions of urbanization, especially composite atmospheric pollution problems, such as dust haze and photochemical smog (Adams et al., 2005; Amos et al., 2010). From late 2011 to early 2012, hazy weather was observed for the first time in East and Central China, and the worst pollution since historical observation began occurred in 2013 (Anselin, 1988). This has materially affected the atmospheric environment and public health in cities and other areas (Anselin and Kelejian, 1997; Chameides et al., 1999), and atmospheric pollution has become a major hindrance to the sustainable development of cities in the country (Chan and Yao, 2008). Scientific understanding the characteristics and driving forces of urban atmospheric pollution would provide a reference for formulating and implementing regional preventive measures.

Research by geographers into urban air quality has focused on two aspects. One is the change characteristics of air quality. Such research already covers all spatial dimensions, including most cities nationwide (Cliff and Ord, 1982; Damodar, 2013), typical city clusters (Fang and Wang, 2011; Grossman and Krueger, 1992), and individual cities (Han et al., 2014; Huang and Fang, 2003). However, this study lacks comparative analysis on different spatiotemporal scales. Zhao et al. compared differences of air quality between cities and countryside (Huang et al., 2009), and Wang et al. analyzed changes of urban air quality during major festival activities (Hyslop, 2009). According to the latter authors, regional differentiation of air pollution intensity is mainly caused by unbalanced urbanization. In regions with rapid urbanization and heavy population, air pollution is much greater than in regions with less urbanization ( $\mathrm{Li}$ et al., 2012). Because of this, the eastern coastal regions of China have become the focus of research (Li, 2011; Luo et al., 2000; Ma and Zhang, 2014; Panayotou, 2001; Patton et al., 2014; Peng et al., 2016; Pope and Dockery, 2006). The other research aspect is one that emphasizes influential factors. Natural factors mainly include meteorological conditions (Qiao et al., 2015; Sarrat et al., 2006), wind fields (Tian et al., 2014), sandstorms (Wang et al., 2015), fog (Wang and Liu, 2016), and urban heat island effects (Wang et al., 2011). Social and economic factors mainly include economic growth (Wang et al., 2014; Wang and Hao, 2012), urbanization (Wang et al., 2005), industrial development (Wang et al., 2001), transport (Wang et al., 2008), energy structure (Wang et al., 2015), and oil price changes (Wing, 2008). However, current research often ignores the influences direction and intensity differentiation of various factors on air quality in different regions. The theoretical significance of targeting this issue is exploration of the evolution and inherent mechanism of the human-earth relationship, and the realistic significance is to provide a scientific basis for formulating air pollution prevention and control measures according to circumstances.

\section{Research regions and methods}

\subsection{Research regions and data sources}

In 2012, China published new Ambient Air Quality Standards (GB3095-2012), with air 
quality monitoring data changed from Air Pollution Index (API) to Air Quality Index (AQI). In 2013, 74 cities in the country were monitored for air quality according to the new standard. This number increased to 161 in 2014. These cities are the major research objects of the present paper. Atmospheric pollution has characteristic for regional dissemination and the air quality of individual cities is affected by pollution from adjacent cities (Li et al., 2011; Wu et al., 2011). To discover the overall pattern of urban air quality in China, we divided the 161 cities by region (Figure 1). Because Haikou and Sanya are on an island to the south of China and Lhasa is on the Qinghai-Tibet Plateau, the influence of socioeconomic activities in the major urbanization regions of China on the air quality of those three cities is extremely weak. Therefore, those cities were not classified into any region.

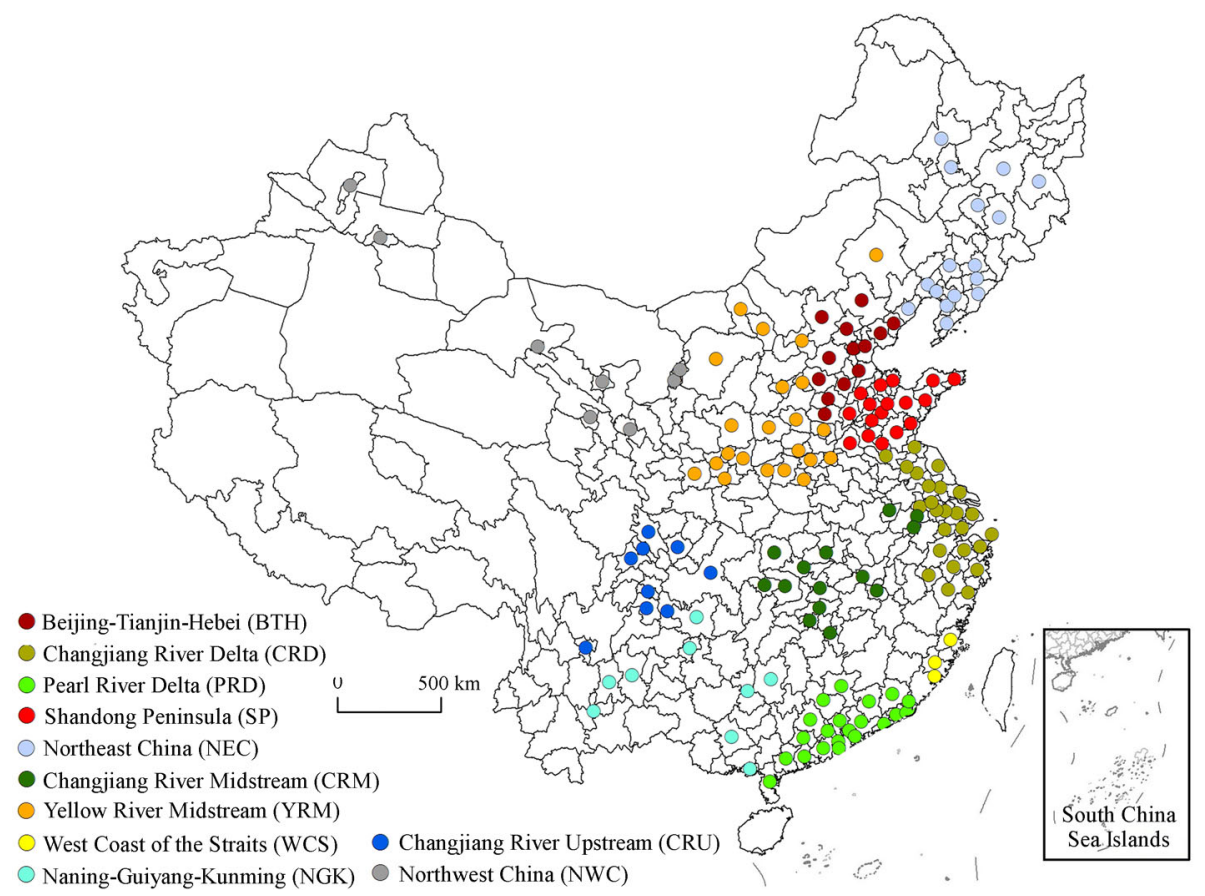

Figure 1 Descriptions of the study area

Research data included the monthly Air Quality Composite Index (AQCI) of 74 cities (2013-2014) published by China National Environmental Monitoring Center, daily AQI of 161 cities (2014) published by the Environmental Protection Department Data Center, and the daily and hourly Air Quality Composite Index (AQCI) of 74 cities (2013-2014) from the SinaWeibo "China City Air Pollution Ranking". Data of socioeconomic development were mainly from the China City Statistical Yearbook 2014, China Urban Construction Statistical Yearbook 2013, Major Data Bulletin of Secondary National Scientific Research and Experiment Development Resources Checking of China, and Statistical Yearbooks (2012) of provinces (municipalities and regions).

\subsection{Spatial effect check model of air quality}

\subsubsection{Global autocorrelation model}

The global autocorrelation model is used to describe the overall distribution of urban air 
quality changes for determining whether urban air quality changes have any spatial clustering. The common test statistic is Global Moran's I (Xi and Liang, 2015; Xu et al., 1999), calculated by

$$
\text { Moran's } I=\frac{n \sum_{i=1}^{n} \sum_{j=1}^{n} W_{i j}\left(x_{i}-\bar{x}\right)\left(x_{j}-\bar{x}\right)}{\left(\sum_{i=1}^{n} \sum_{j=1}^{n} W_{i j}\right) \sum_{j=1}^{n}\left(x_{i}-\bar{x}\right)^{2}}(i \neq j)
$$

where $x_{i}$ and $x_{j}$ are air quality observation values of cities $i$ and $j ; n$ is the total number of cities; $W_{i j}$ is the spatial weight, defined by adjacency criteria, i.e., when $i$ and $j$ are adjacent, $W_{i j}=1$, otherwise $W_{i j}=0 ; i=1,2, \ldots, n ; j=1,2, \ldots, m ; \bar{x}$ is the mean of $x$.

The value of Global Moran's $I$ ranges from -1 to 1 , With $\mathrm{I}$, it is possible to ascertain the clustering level of urban air quality. $I>0$ indicates spatially positive correlation, i.e., the regional urban air quality shows a clustered distribution. $I<0$ indicates spatially negative correlation, i.e., that quality shows a scattered or even distribution. $I=0$ indicates no spatial correlation, i.e., the quality shows an irregular random distribution. Significance can be tested using the standard statistic $Z$ test, with its calculation as follows.

$$
Z=\frac{I-E(I)}{\sqrt{\operatorname{Var}(I)}}
$$

When a $95 \%$ confidence level is selected, $|Z|>1.96$, indicating significant spatial autocorrelation.

\subsubsection{Local autocorrelation model}

Local autocorrelation indicates correlation between the air quality of one regional unit and that of an adjacent unit, with the calculation as follows.

$$
\text { LocalMoran's } I=\frac{n\left(x_{i}-\bar{x}\right) \sum_{j=1}^{m} W_{i j}\left(x_{j}-\bar{x}\right)}{\sum_{i=1}^{n}\left(x_{i}-\bar{x}\right)^{2}}(i \neq j)
$$

where, $x_{i}$ and $x_{j}$ are the air quality observations of cities $i$ and $j ; n$ is the number of cities; $W_{i j}$ is the spatial weight; $i=1,2, \ldots, n ; j=1,2, \ldots, m ; m$ is the number of cities geographically adjacent to city $i$. The spatial association modes of local autocorrelation include four types, $\mathrm{HH}, \mathrm{HL}, \mathrm{LH}$ and HL, for which the spatial meaning is respectively: HH (LL) cluster type means local Moran's $I$ is a positive value, indicating positive spatial autocorrelation between the air quality of a city and its adjacent cities, i.e., cities of high (low) air quality cluster spatially; HL (LH) cluster type means local Moran's $I$ is a negative value, indicating negative spatial autocorrelation between adjacent cities, i.e., cities of high (low) air quality surrounded by cities of low (high) air quality.

\subsection{Urban air quality driving force model based on spatial effect}

\subsubsection{Setting of basic model}

According to available theories and empirical research findings, by selecting the population 
density $\left(X_{1}\right)$, per capita GDP $\left(X_{2}\right)$, urbanization level $\left(X_{3}\right)$, ratio of industrial output in GDP $\left(X_{4}\right)$, total energy consumption $\left(X_{5}\right)$, total civil vehicles automobiles $\left(X_{6}\right)$, ratio of environmental protection investment in GDP $\left(X_{7}\right)$, and ratio of R\&D expenditures in GDP $\left(X_{8}\right)$, we explore the influence of population clustering, economic development, urbanization, industrialization, energy consumption, social development, environmental regulation and technological progress on urban air quality changes. In view of the long-term process of regional development, a nonlinear inverted "U-shaped" curve relationship is observed between economic development, urbanization and the ecological environment (Wang et al., 2014; Wang and Hao, 2012; Xu et al., 2005). According to the current development stage in China, we primarily assumed that within a short period, population clustering, economic development, urbanization, industrialization, social development, environmental regulation and technological progress are linearly correlated with urban air quality. Based on the above, the basic analytical model is established as follows.

$$
\ln Y=\alpha_{0}+\alpha_{1} \ln X_{1}+\alpha_{2} \ln X_{2}+\alpha_{3} X_{3}+\alpha_{4} X_{4}+\alpha_{5} \ln X_{5}+\alpha_{6} \ln X_{6}+\alpha_{7} X_{7}+\alpha_{8} X_{8}+\varepsilon
$$

where $Y$ is the Air Quality Index (AQI); $X_{1}, \ldots, X_{8}$ are sequentially the population density, per capita GDP, urbanization level, ratio of industrial added-value in GDP, total energy consumption, total private automobiles, ratio of environmental protection investment in GDP, and ratio of R\&D expenditures in GDP; $\alpha\left[\alpha_{0}, \alpha_{1}, \ldots, \alpha_{8}\right]$ is the model parameter to be estimated; $\varepsilon$ is stochastic error of the model, subject to normal distribution $\mathrm{N}\left(0, \sigma^{2}\right)$. The natural logarithm is taken for AQI, population density $\left(X_{1}\right)$, per capita GDP $\left(X_{2}\right)$, total energy consumption $\left(X_{5}\right)$, and total private automobiles $\left(X_{6}\right)$, to reduce the effect of heteroscedasticity on model estimates (Yang et al., 2014).

\subsubsection{Setting of spatial effect model}

In actuality, urban air quality is not a completely independent observation, the change of which is subject to surrounding areas, so the spatial effect cannot be ignored. Econometric regression models with consideration of spatial effects include two types, the Spatial Lag Model (SLM) and Spatial Error Model (SEM) (Zakey et al., 2006). To select a spatial model, it is necessary to estimate the constraint model, with consideration of spatial correlation using the least-square method (OLS) and model selection by comparing the significance of the Lagrange multiplier. If the Lagrange multiplier LM (lag) is statistically more significant than LM (error) and R-LM (lag) is more significant than R-LM (error), we select the spatial lag model for analysis. The expression of the spatial lag model based on the basic model is

$$
\ln Y=\rho W Y+\alpha_{0}+\alpha_{1} \ln X_{1}+\alpha_{2} \ln X_{2}+\alpha_{3} X_{3}+\alpha_{4} X_{4}+\alpha_{5} \ln X_{5}+\alpha_{6} \ln X_{6}+\alpha_{7} X_{7}+\alpha_{8} X_{8}+\varepsilon
$$

where $Y$ is the AQI; $\rho$ is the spatial regression coefficient; $W$ is the spatial weight matrix of order $n \times 1 ; X_{1}, \ldots, X_{8}$ are eight independent variables; $\alpha\left[\alpha_{0}, \alpha_{1}, \ldots, \alpha_{8}\right]$ is the model parameter to be estimated; $\varepsilon$ is the stochastic error.

If LM (error) is statistically more significant than LM (lag) and R-LM (error) is more significant than R-LM (lag), we select the spatial error model for analysis. The expression of the spatial error model based on the basic model is

$$
\begin{gathered}
\ln Y=\alpha_{0}+\alpha_{1} \ln X_{1}+\alpha_{2} \ln X_{2}+\alpha_{3} X_{3}+\alpha_{4} X_{4}+\alpha_{5} \ln X_{5}+\alpha_{6} \ln X_{6}+\alpha_{7} X_{7}+\alpha_{8} X_{8}+\varepsilon \\
\varepsilon=\lambda W \varepsilon+\mu
\end{gathered}
$$

where $Y$ is the AQI; $\lambda$ is the spatial error coefficient; $W$ is the spatial weight matrix of order $n \times$ $1 ; X_{1}, \ldots, X_{8}$ are eight independent variables; $\alpha\left[\alpha_{0}, \alpha_{1}, \ldots, \alpha_{8}\right]$ is the model parameter to be estimated; $\varepsilon$ is the stochastic error; $\mu$ is the stochastic error vector of a normal distribution. 
Owing to the endogeneity of spatial regression model independent variables, the maximum likelihood method is used to estimate the model parameter. Both the spatial distance weight is calculated and spatial model run in GeoDa software (Zakey et al., 2006).

\section{Analysis of findings}

\subsection{Spatiotemporal evolution characteristics of urban air quality in China}

3.1.1 The urban air quality is worsening overall and there is an obvious deteriorating trend of high-pollution regions

By comparing AQCI of 74 cities in 2013 and 2014, we analyzed the annual change characteristics of urban air quality. Nationally, the annual mean of AQCI in 2013 was 4.46, which rose to 6.08 in 2014. Comparing the monthly mean of the two years, it declined slightly only in January and rose clearly in other months, indicating an overall worsening trend of air quality of the 74 cities. The monthly change of AQCI in the two years was basically similar. The January mean was the maximum in the year, after which it decreased continually, with minima in August and September and then monthly increase thereafter. Regionally, the annual mean of AQCI for 11 regions in 2014 was larger than that in 2013. All monthly means of four regions, the Pearl River Delta, Nanning-Guiyang-Kunming, Changjiang River Upstream and West Coast of the Straits, were larger than those of the same months in 2013 (Figure 2). Regional monthly means of AQCI were also basically in line with the pattern of "high in winter and low in summer, declining in spring and rising in autumn.
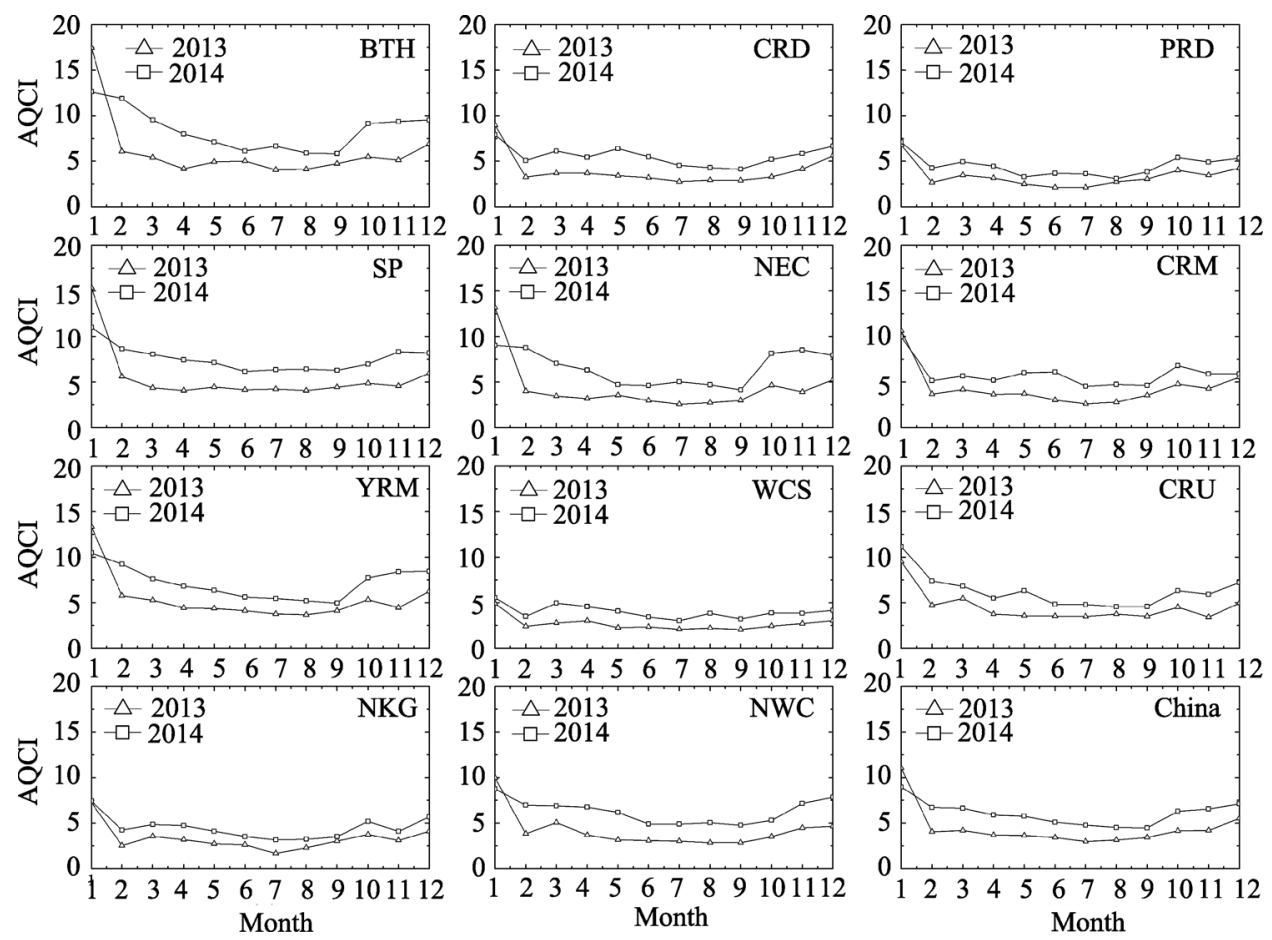

Figure 2 Monthly variations in air quality comprehensive index (AQCI) in China in 2013 and 2014 
Comparing annual means of AQCI by region, regions with large values were Beijing, Tianjin and Hebei, the Shandong Peninsula, Northeast China, and Yellow River Midstream. Regions with small values include the Pearl River Delta, West Coast of the Straits, and Nanning-Guiyang-Kunming. This reveals that the air quality of the northern regions is poorer than that of the southern regions. The error coefficient was used to measure the change of AQCI annual means in 11 regions. The poorest air qualities were in the order of Northeast China (0.6063), Northwest China (0.5221), Beijing-Tianjin-Hebei (0.4897), West Coast of the Straits (0.4882), Shandong Peninsula (0.4615), Changjiang River Delta (0.4333), and Yellow River Midstream (0.4040), mainly in regions of high AQCI. In other words, in regions with more serious air pollution, the worsening trend was more obvious.

3.1.2 The percentage of days compliance of urban air quality increased but air pollution deteriorated

In 2013, the percentage of average days of compliance in cities nationwide was $60.5 \%$, with light and medium pollution days constituting $30.90 \%$ and heavy and serious pollution $8.6 \%$. In 2014 , that percentage was $66.03 \%$, an increase of $5.53 \%$ compared with 2013 , with light and medium pollution contributing $28.37 \%$ and heavy and serious pollution $5.6 \%$. Comparing the two years, pollution days declined for all grades, with increases of compliance days of air quality and of the percentage of compliance days. However, the annual mean of national AQCI in 2014 rose somewhat in comparison with 2013, indicating that pollution increased and weather of heavy pollution was not under effective control.

According to the Technical Regulation on Ambient AQI (on Trial) (HJ633-2012), the index includes six grades: $0<\mathrm{AQI}<50$, air quality is excellent; $51<\mathrm{AQI}<100$, air quality is fine; $101<\mathrm{AQI}<150$, air quality is slight pollution; $151<\mathrm{AQI}<200$, air quality has medium pollution; $201<\mathrm{AQI}<300$, air quality has heavy pollution; $\mathrm{AQI}>300$, air quality has serious pollution. By determining the percentage of annual days of various pollution grades by region from January to December 2014 (Figure 3), it may be seen that the regions with larger percentages of pollution days among total annual days were sequentially Beijing-Tianjin-Hebei, Shandong Peninsula, Yellow River Midstream, Changjiang River Midstream, Northwest China, Changjiang River Upstream, Changjiang River Delta, Northeast China, Nanning-Guiyang-Kunming, Pearl River Delta and West Coast of the Straits, with $66.58 \%, 64.93 \%, 44.93 \%, 38 \%, 37 \%, 31 \%, 30.14 \%, 29.04 \%, 14 \%, 9.32 \%$ and $4 \%$, respectively. The percentage of pollution days in the Beijing-Tianjin-Hebei region by grade was higher than the national average, and it was the region with most serious pollution in China. It was followed by the Shandong Peninsula, with the percentage of pollution days by grade only $2.47 \%$ lower than Beijing-Tianjin-Hebei.

3.1.3 Changes of urban air quality show certain temporal coupling with regional socioeconomic activities

To minimize the impact of spring sandy and dusty weather, summer rainfall and winter northern heating, taking October 2, 2014 as an example, we analyzed the 24-hour change of urban air quality by region (Figure 4). According to the all-day AQI change curve, the 11 regions can be classified into two types. One is regular change, characteristic of regional production and life activities as "work from dawn to dusk," with urban air quality basically "relatively poor at dawn and relatively good at dusk". Such regions mainly include 

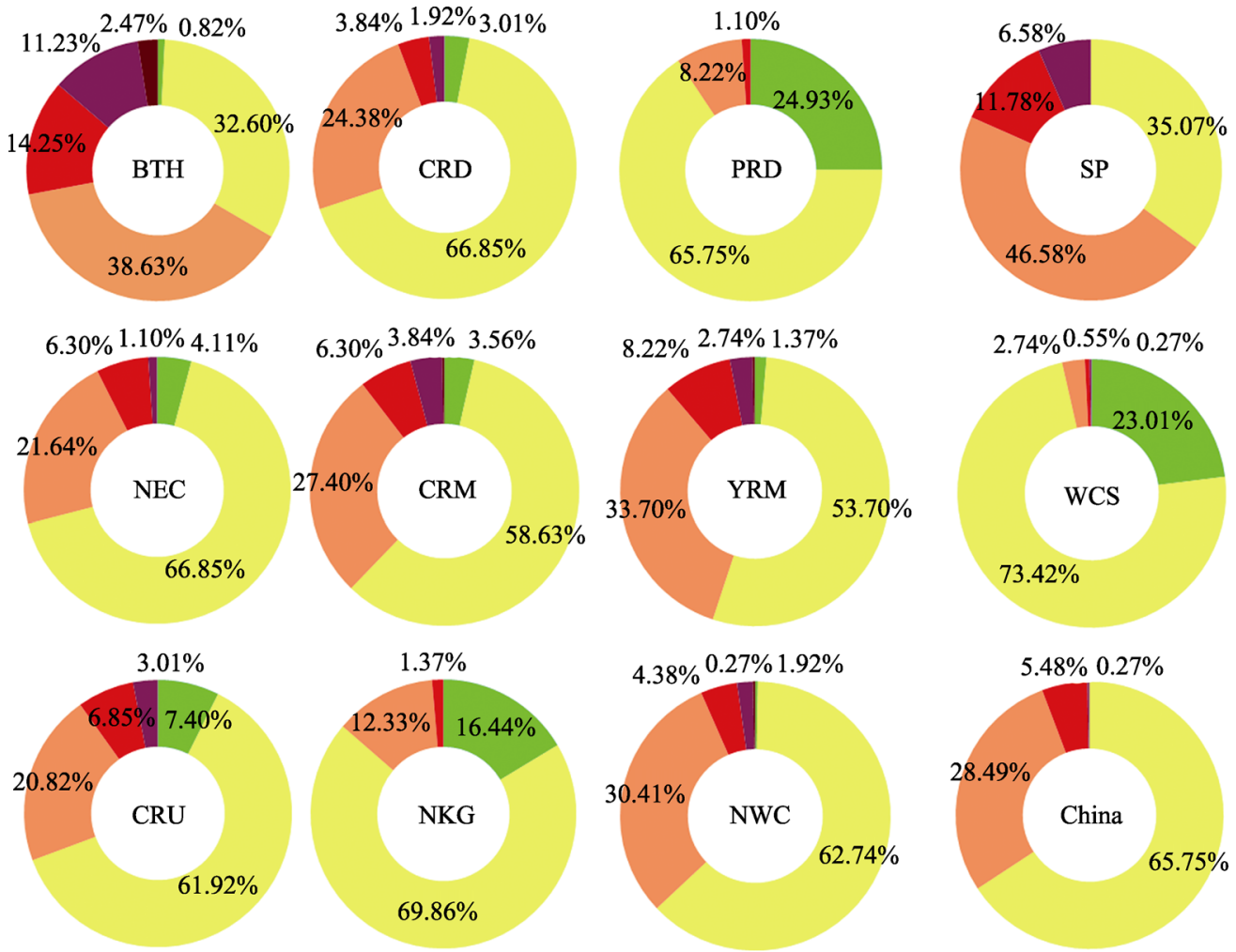

Excellent Fine Slight pollution

Medium pollution

Heavy pollution

Serious pollution

Figure 3 The proportions of days with different air quality levels at national and regional scales in China in 2014

Beijing-Tianjin-Hebei, Changjiang River Delta, Pearl River Delta, Northeast China, West Coast of the Straits, and Nanning-Guiyang-Kunming. From 06:00 to 08:00 and 18:00 to 20:00, owing to the impact of heavy travel to and from the office, the urban AQI continually increased. For regions such as Beijing-Tianjin-Hebei, Changjiang River Delta, and Pearl River Delta, the all-day AQI peak was from 08:00 to 09:00. For the West Coast of the Straits, that peak was at 14:00. For regions such as Northeast China and Nanning-Guiyang-Kunming, the peak was at 23:00. The other was the type of exceptional change, mainly including such regions as the Shandong Peninsula, Changjiang River Midstream, Yellow River Midstream, Northwest China, and Changjiang River Upstream. For the regions of this type, during peak hours of travel, the change of AQI was not as prominent and for most, the all-day AQI peak appeared around midnight, at 24:00-02:00 in regions such as the Shandong Peninsula, Changjiang River Midstream, and Yellow River Midstream. The Shandong Peninsula, Changjiang River Midstream, Yellow River Midstream and other regions are key cluster regions of heavy and chemical industry along the coast and rivers of China. There, owing to pressure for emissions reduction, industrial production activities are frequent during the night and such increased industrial emissions may a factor causing the urban air quality decline.

3.1.4 Urban air pollution shows a spatial pattern of "heavy in the east and light in the west, and heavy in the north and light in the south," and regional integration is obvious 

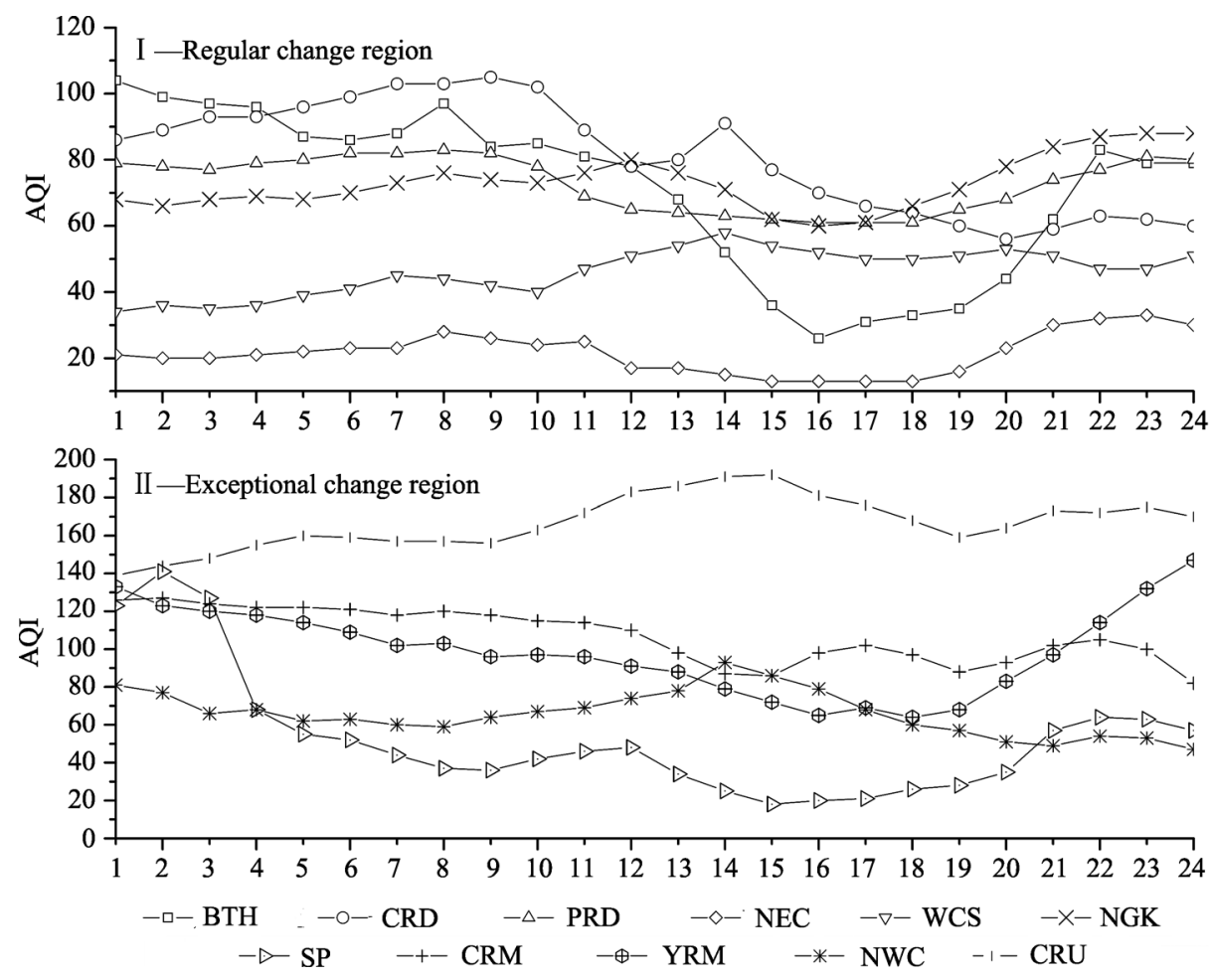

Figure 4 The hourly variations of AQI on October 2, 2014 in different regions

Comparative analysis of the spatial distribution of AQI means in 161 cities nationwide in 2014 shows an overall a situation of gradual decrease from coast to interior and from north to south, with cities of large values clustered along the eastern coast and Yellow River, with the maximum in the region of Beijing-Tianjin-Hebei (Figure 5). In eastern coastal regions with relatively serious pollution, the AQI of cities near the sea is smaller than that of cities farther from the sea. For instance, the AQI of Tianjin is smaller than that of Beijing and Shijiazhuang, and the AQI of Shanghai is smaller than that of Nanjing and Hangzhou. The AQI of Zhuhai and Shenzhen is smaller than that of Guangzhou, indicating that the coastal environment has a major influence on urban air quality. The global autocorrelation analysis was conducted for the air quality of 161 cities (Figure 6). Moran's $I$ was 0.6621 , and the 0.05 -level significance test indicates a significant positive correlation of urban air quality in China, i.e., the

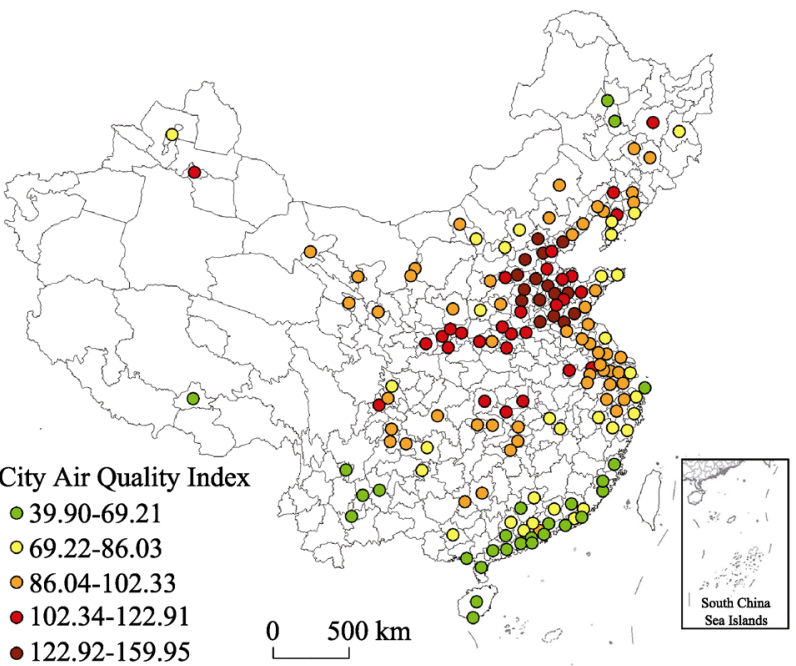

Figure 5 Spatial patterns of AQI in Chinese cities in 2014 


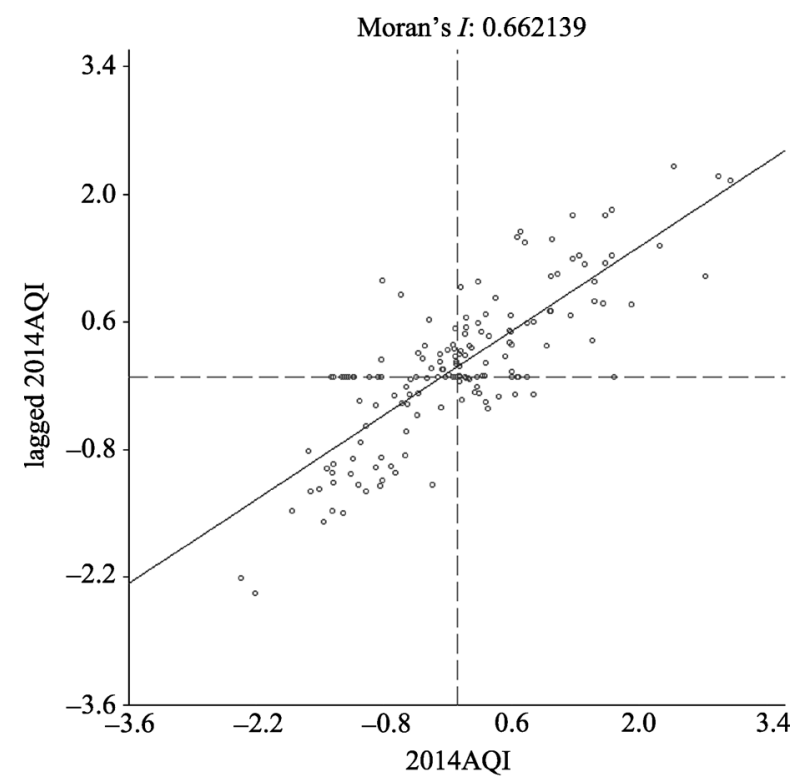

Figure 6 Global autocorrelation of AQI in Chinese cities in 2014

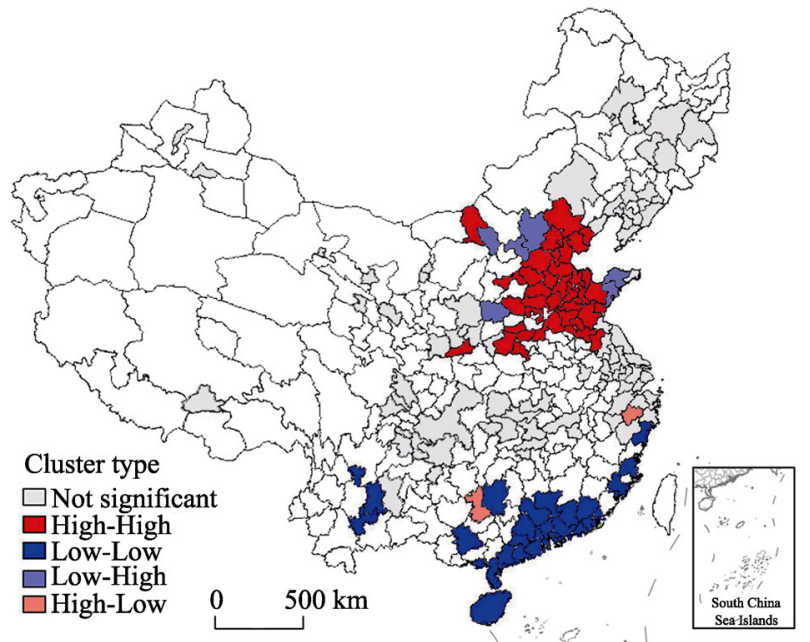

Figure 7 Local autocorrelations of AQI in Chinese cities in 2014

distribution, urban air quality distributions are classified into six categories, as follows: Category I: Beijing-Tianjin-Hebei, in which the mean of urban AQI was first among all the 11 regions, indicating substantial overall pollution. The AQI for most cities was larger the mean AQI, revealing significant integration of regional atmospheric pollution; Category II: Shandong Peninsula, for which the mean urban AQI was second to Beijing-Tianjin-Hebei. This also indicates substantial overall pollution. The AQI for most cities was smaller than the mean AQI, indicating a significant impact of a limited number of cities with serious pollution on regional air pollution; Category III: Northeast China and Changjiang River Upstream, for which the mean urban AQI was relatively large and the numbers of cities

AQI distribution shows an obvious clustering situation in which largevalue regions are adjacent to each other, as are small-value regions. After further analysis of spatial local autocorrelation (Figure 7), we determined that Beijing-Tianjin-Hebei, Shandong Peninsula, Liaodong Peninsula and Central China city clusters were central areas of AQI HH "hot points". The Pearl River Delta, West Coast of the Straits, and Hainan are central regions of LL "cold points". Small-value areas surrounded by large-AQI areas (LH "heterogeneous points") were rare, mainly around Beijing-Tianjin-Hebei and the Shandong Peninsula. Large-value areas surrounded by small-AQI areas (HL heterogeneous points) were mainly in Nanning-Guiyang-Kunming and the Changjiang River Delta. Obviously, regional integration of urban atmospheric pollution in China is significant, and it is increasingly important to implement regional joint prevention and control in atmospheric pollution governance.

3.1.5 Overall extent and distribution of regional urban air pollution have obviously different characteristics

Figure 8 shows an AQI box distribution diagram of cities by region in 2014. According to AQI scatter and 


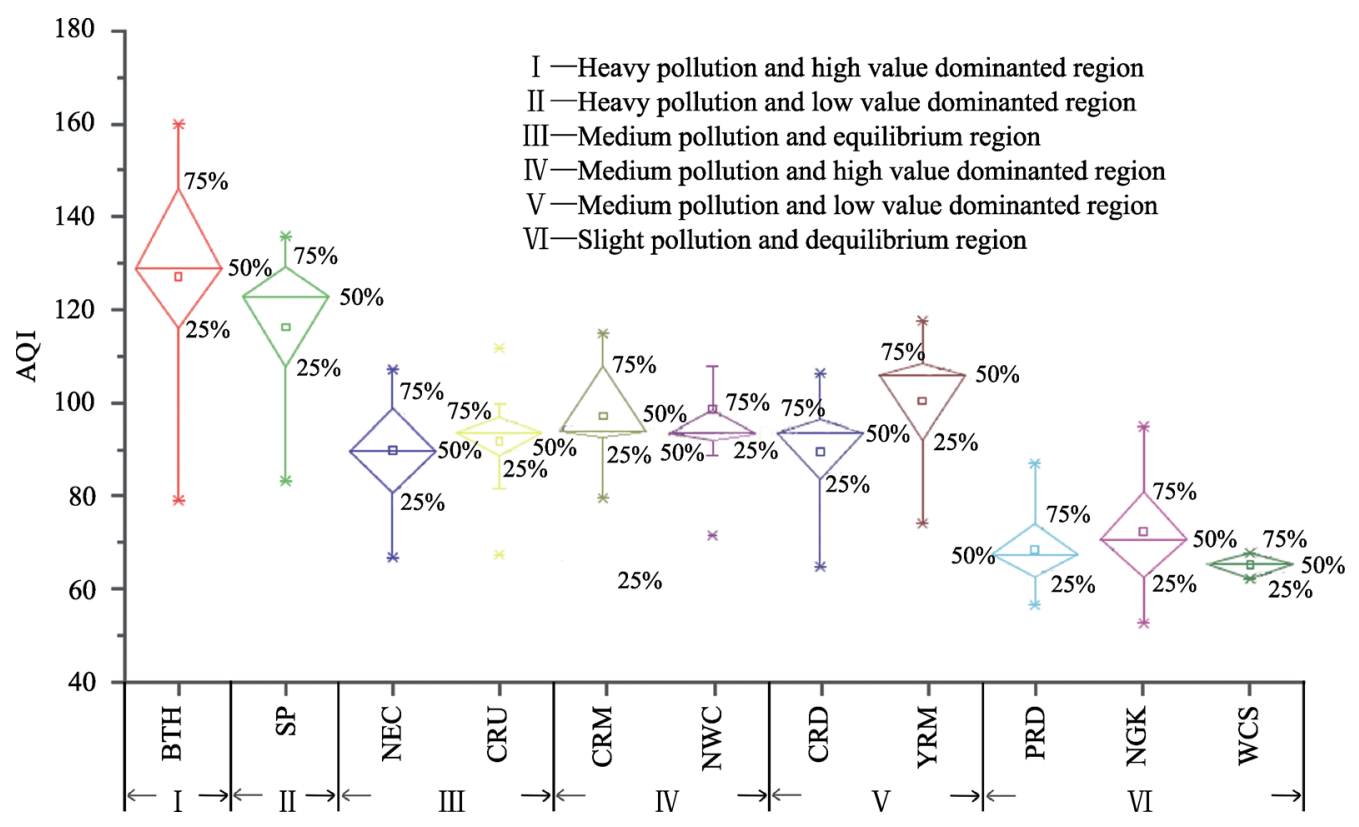

Figure 8 The statistical distributions of AQI in different regions in 2014

above and below the mean were nearly the same; Category IV: Changjiang River Midstream and Northwest China, for which the mean urban AQI was relatively large and the AQI for most cities was larger than the mean AQI; Category V: Changjiang River Delta and Yellow River Mid- stream, for which the mean of urban AQI was relatively large and the AQI for most cities was smaller than the mean AQI; Category VI: Pearl River Delta, Nanning-Guiyang-Kunming and West Coast of the Straits, where atmospheric pollution was relatively weak.

\subsection{Socioeconomic drivers for evolution of urban air quality in China}

\subsubsection{Analysis of socioeconomic factors for evolution of urban air quality}

Using AQIs of 161 cities in 2014 and socioeconomic data of various cities in 2013, we analyzed the socioeconomic drivers for change of urban air quality according to the above formula. We performed the global autocorrelation test, with Moran's I at 0.6621, showing significant spatial correlation. By analyzing correlation between different independent variables in SPSS software, we observed the correlation coefficient was $<0.8$. Then, OLS was used to do model estimation, and it was observed that the variance inflation factor (VIF) of each variable was $<3.5$ (much smaller than the critical value 10). This indicates the model has no multiple collinear problem (Yang et al., 2014). OLS was used to estimate the constraint model with consideration of spatial correlation, showing that the LM (lag) was statistically more significant than LM (error). Moreover, steady R-LM (lag) was more significant than RLM (error), so the spatial lag model was selected for analysis, with model estimates shown in Table 1. From OLS estimation, $\mathrm{R}^{2}=0.284$ and, in the spatial lag model estimate, $\mathrm{R}^{2}=0.691$. Clearly, consideration of spatial correlation greatly enhances the fit of the model. From findings of the spatial lag model and based on comprehensive consideration of such factors as population clustering, economic development, urbanization, industrialization, energy con- 
Table 1 Estimation results of the socioeconomic factors of AQI at the national level

\begin{tabular}{|c|c|c|c|c|}
\hline \multirow{2}{*}{$\begin{array}{c}\text { Independent } \\
\text { variable coefficient }\end{array}$} & \multicolumn{2}{|c|}{ OLS model } & \multicolumn{2}{|c|}{ Spatial lag model } \\
\hline & Coefficient value & $\mathrm{T}$ value & Coefficient value & $\mathrm{Z}$ value \\
\hline$\alpha_{0}$ & 0.001 & 0.012 & $-0.055 * * *$ & -1.193 \\
\hline$\alpha_{1}$ & 0.062 & 0.767 & 0.038 & 0.691 \\
\hline$\alpha_{2}$ & $-0.427 * * *$ & -4.155 & $-0.242 * * *$ & -3.518 \\
\hline$\alpha_{3}$ & -0.011 & -0.140 & -0.019 & -0.356 \\
\hline$\alpha_{4}$ & $0.200 * *$ & 2.303 & $0.108^{*}$ & 1.892 \\
\hline$\alpha_{5}$ & $0.458 * * *$ & 3.711 & $0.265^{* * *}$ & 3.322 \\
\hline$\alpha_{6}$ & 0.056 & 0.413 & 0.079 & 0.908 \\
\hline$\alpha_{7}$ & -0.107 & -1.363 & -0.066 & -1.306 \\
\hline$\alpha_{8}$ & $0.199 * *$ & 2.035 & $0.104 *$ & 1.645 \\
\hline$\varepsilon$ & - & - & $0.657 * * *$ & 13.967 \\
\hline $\mathrm{R}^{2}$ & 0.284 & - & 0.691 & - \\
\hline Log likelihood & - & - & -133.578 & - \\
\hline
\end{tabular}

Note: * indicates significance under $10 \%, * *$ indicates significance under $5 \%$, *** indicates significance under $1 \%$

sumption, social development, environmental regulation and technological progress, population density, urbanization, total civil vehicles automobiles, environmental protection investment had no significant impact on changes of urban air quality in China. Total energy consumption, percentage of industrial added value in GDP, and percentage of R\&D expenditures in GDP showed significant positive correlation with AQI. With those three increasing by $1 \%$, the AQI increased by $0.265 \%, 0.108 \%$ and $0.104 \%$ respectively. Energy consumption, mainly of coal resources, is an important cause of atmospheric environment degradation. As tested and verified in many studies, technological progress shows co-growth with this degradation, and is termed the "rebound effect" (Zhang and Fan, 2011). Per capita GDP shows significant negative correlation with the AQI. With per capita GDP increasing by 1\%, the AQI fell by $0.242 \%$ and urban air quality improved, i.e., economic development ameliorated the urban atmospheric environment. In view of the experiences of western developed countries, per capita GDP of 6000-8000 USD is the critical range for ambient air quality to improve. In 2013, China's urban per capita GDP reached 6880 USD, within the aforementioned range for improved air quality. According to the analytical determination of correlation between China's per capita GDP and AQI of 161 cities, the relationship between economic development and atmospheric environment evolution has already exceeded the top point of Environmental Kuznets Curve (EKC). However, because of the large regional gap in China, there is a large difference of influence degree of economic development for air quality in regions with different development stages.

\subsubsection{Differentiation of socioeconomic factors for evolution of regional urban air quality}

To avoid instability of the model from the limited number of samples, with comprehensive consideration of factors such as pollution severity, economic development stage and geographic distribution, the four regions of Beijing-Tianjin-Hebei $\left(\mathrm{M}_{1}\right)$, Changjiang River Delta $\left(\mathrm{M}_{2}\right)$, Pearl River Delta $\left(\mathrm{M}_{3}\right)$, and Shandong Peninsula $\left(\mathrm{M}_{4}\right)$ were selected for case analysis, national scope was represented by $\mathrm{M}_{5}$. For the independent variables, four indicators were chosen that are nationally important, i.e., economic growth, energy consumption, industri- 
alization, and technological progress. Upon testing, the four aforementioned regions were all applicable to the spatial lag model, with model estimates shown in Table 2.

Table 2 Estimation results of the socioeconomic factors of AQI in different regions

\begin{tabular}{|c|c|c|c|c|c|c|c|c|c|c|}
\hline \multirow{2}{*}{$\begin{array}{c}\text { Independent } \\
\text { variable } \\
\text { coefficient }\end{array}$} & \multicolumn{2}{|l|}{$M_{1}$} & \multicolumn{2}{|l|}{$M_{2}$} & \multicolumn{2}{|c|}{$M_{3}$} & \multicolumn{2}{|l|}{$M_{4}$} & \multicolumn{2}{|c|}{$M_{5}$} \\
\hline & $\begin{array}{l}\text { Coefficient } \\
\text { value }\end{array}$ & $Z$ value & $\begin{array}{c}\text { Coefficient } \\
\text { value }\end{array}$ & $Z$ value & $\begin{array}{c}\text { Coefficient } \\
\text { value }\end{array}$ & $Z$ value & $\begin{array}{c}\text { Coefficient } \\
\text { value }\end{array}$ & $Z$ value & $\begin{array}{l}\text { Coefficient } \\
\text { value }\end{array}$ & $Z$ value \\
\hline$\alpha_{0}$ & -0.042 & -0.388 & $-0.244 *$ & -1.785 & -0.004 & -0.022 & -0.033 & -0.260 & -0.055 & -1.166 \\
\hline$\alpha_{2}$ & $-0.416^{*}$ & -1.893 & $-0.994 * * *$ & -3.646 & 0.414 & 0.883 & $-0.457 * *$ & -2.213 & $-0.252 * * *$ & -3.814 \\
\hline$\alpha_{4}$ & $1.255 * * *$ & 5.014 & $0.375 * * *$ & 2.580 & 0.179 & 0.854 & 0.237 & 1.430 & $0.104 * *$ & 2.097 \\
\hline$\alpha_{5}$ & -0.195 & -0.832 & $0.404 *$ & 1.792 & $0.545^{*}$ & 1.705 & 0.217 & 1.353 & $0.330 * * *$ & 5.566 \\
\hline$\alpha_{8}$ & $1.644 * * *$ & 5.595 & $0.953 * * *$ & 3.010 & $-0.731 *$ & -1.777 & 0.142 & 0.749 & $0.121^{* *}$ & 1.961 \\
\hline$\varepsilon$ & $0.623 * * *$ & 3.667 & $0.312^{*}$ & 1.742 & $0.082 * * *$ & 0.301 & $0.751 * * *$ & 5.395 & $0.658 * * *$ & 13.870 \\
\hline$R^{2}$ & 0.850 & - & 0.549 & - & 0.279 & - & 0.711 & - & 0.682 & \\
\hline $\begin{array}{c}\log \\
\text { likelihood }\end{array}$ & -6.516 & - & -25.476 & - & -25.869 & - & -14.809 & - & -135.697 & \\
\hline
\end{tabular}

Note: $*$ indicates significance under $10 \%, * *$ indicates significance under $5 \%, * * *$ indicates significance under $1 \%$

Beijing-Tianjin-Hebei: The percentage of R\&D expenditures in GDP and industrialization show a significant positive correlation, i.e., with the indicator value increasing, AQI increases and atmospheric environmental quality declines. Per capita GDP has a negative correlation with the AQI, i.e., with the indicator value increasing, AQI decreases and the atmospheric environment improves. In 2013, per capita GDP in the Beijing-Tianjin-Hebei region reached 8548 USD and the level of urbanization was high relative to national urban development (Zhao et al., 2012). Thus it can be confidently asserted that the relationship between economic development and the ecological environment has passed the turning point of the EKC; Changjiang River Delta: The percentage of R\&D expenditures in GDP, energy consumption, and industrialization show positive correlation with AQI, and per capita GDP shows a negative correlation. In 2013, per capita GDP in the Changjiang River Delta region reached 13,052 USD, so it can be asserted that the relationship between economic development and the ecological environment has passed through the EKC turning point; Pearl River Delta: Energy consumption had a significant positive correlation with AQI, and the percentage of R\&D expenditures in GDP had a significant negative correlation. In view of the periodic rule for technological progress, the higher the level of technological development, the greater the total factor productivity is, the greater the resource utilization is, and the lower the unit output emission is. Guangdong is one of the regions with the highest development level of new- and high-technology industry in China (Zhao et al., 2009), so technological progress has promoted the improvement of air quality; Shandong Peninsula: Per capita GDP had a significant negative correlation with AQI, i.e., the high per capital GDP of its cities, the lower the AQI, and the more excellent their air quality.

\subsubsection{Socioeconomic drivers for the evolution of urban air quality in China}

To conclude the above, at the national level, considering such factors as population clustering, economic growth, urbanization, industrialization, energy consumption, social development, environmental regulation and technological progress, four factors such as economic development, industrialization, energy consumption and technological progress show a sig- 


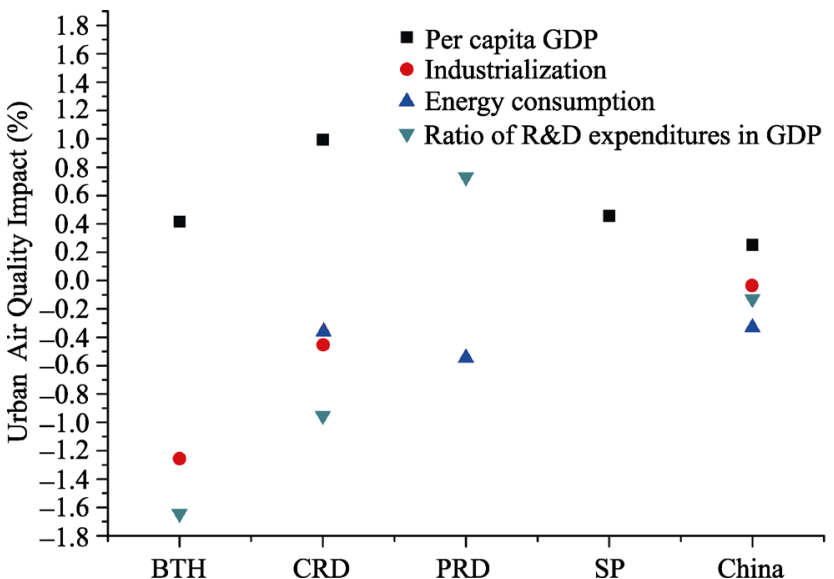

Figure 9 Socioeconomic factors of air quality in different regions Note: Positive value of variable represents positive effects on air quality improvement, and vice versa. nificant correlation with changes of urban air quality. Economic development has a positive effect on improvement of atmospheric ambient air quality, industrialization, energy consumption, while technological progress have negative effects on the improvement of atmospheric air quality.

At the regional level, owing to differences in socioeconomic development, the four aforementioned factors varied in terms of significance, direction and strength of influence on urban air quality improvement. Economic development shows a positive effect on this improvement, the higher per capita GDP of a region, the stronger the effect of economic development on the improvement. Industrialization and energy consumption had a negative effect on improvement of urban air quality; the smaller the percentage of industrial added value in GDP, the stronger the negative effect of industrial development on that quality (Figure 9).

The effect direction and strength of technological progress for the improvement of air quality was significantly different for different stages of development. In Beijing-TianjinHebei, Changjiang River Delta and nationwide, the percentage of R\&D expenditures in GDP shows a significant negative correlation with urban air quality, and the strength of negative impact declines accordingly. In the Pearl River Delta region, the percentage of R\&D expenditures in GDP shows a significant positive correlation with urban air quality. Regarding the level of technical development across regions, it was determined as follows. In economically developed regions, while promoting the utilization of resources, technological progress leads to expansion of the scale of regional production activities and an increase in demand for resources and energies. This has a negative impact on the atmospheric environment. In economically undeveloped regions, the mode for technological progress in promoting economic development changes from extensive to central, with a relatively weak negative effect on environmental improvement.

\section{Conclusions and discussion}

\subsection{Conclusions}

(1) As the comparisons of various air quality indexes in 2013 and 2014 show, urban air quality declined significantly nationwide, and the worsening situation in regions with poor air quality became more obvious. The percentage of days compliance of urban air quality increased but air pollution deteriorated. Changes of urban air quality show a clear temporal coupling with regional socioeconomic activities. Urban air pollution shows a spatial pattern of "heavy in the east and light in the west, and heavy in the north and light in the south". 
Regional integration is obvious; the overall extent and distribution of regional urban air pollution have clearly different characteristics. Regarding the development stages of different regions, the formation and evolution of regional air pollution can be basically induced as "the pollution of key cities is aggravated - pollution of those cities spreads - regional overall pollution is aggravated - the key cities lead in pollution governance-regional pollution joint prevention and control is implemented-regional overall pollution is reduced".

(2) From analyzing the socioeconomic driving forces for changes of urban air quality in China, at the national level, energy consumption, industrialization and technological progress are the major factors in the worsening of urban air quality. Economic development is a significant driver for the improvement of that quality. Socioeconomic factors have different driving directions and strengths for improvement of the quality.

(3) According to the analysis and determination of correlation between per capita GDP and AQI of cities in the case regions, the relationship between national economic development and parts of the developed regions have exceeded the top point of EKC. The higher per capita GDP of a region, the stronger its positive effect on economic development is toward urban air quality improvement. In the developed regions, technological progress had an obvious negative impact on the atmospheric environment. In the undeveloped regions, technological progress shows a less negative impact on environmental improvement.

\subsection{Discussion}

Socioeconomic development is a key cause of degrading air quality, which is a widespread viewpoint verified by many studies. However, in view of the analytical results of the present study, with the promotion of economic development and urbanization level, the impact of socioeconomic factors fits the stages of regional development, and shows a significant periodic characteristic as follows. In various stages, the impact of different socioeconomic factors varied. Even in regions of similar socioeconomic development level, because of the impact of complex mechanisms of regional resources and environment plus other factors, the socioeconomic factors again had strongly variable impacts on air quality, in both direction and intensity. Therefore, addressing the means of control for worsening air quality does not mean comprehensively controlling the promotion of economic development and urbanization. However, based on comparative analysis of correlation between socioeconomic factors and air quality, it is necessary to select key factors and define the keynotes and direction of governance by having a grasp of current characteristics of regional development and resource and environmental bases.

The EKC relationship is observed between economic development and ambient changes in China, and most of the regions have not yet passed the turning point of the curve. Thus, the coercive and retarding effects of economic development on the ecological environment may both be observed over a long time in the future. Therefore, it is critical for resolving the conflict between economic development and worsening air quality to lift the development level of most regions, thereby passing the curve turning point in a short time. During this process, to minimize the negative impact of economic development, the key issue is to thoroughly change the mode of that development, and establish as soon as possible resource-saving and environmentally friendly development modes as well as mutual promotion and harmonious development of the economy and the environment. This can be done by 
relying on science, technology and innovation.

Given our limited number of samples, our summary of socioeconomic drivers of urban air quality changes in China is based only on empirical analysis of the country and several case regions. Since it is a systematic project to comprehensively test and verify the influence of socioeconomic development on air quality, it is necessary to accumulate data on a long-term and stable basis and sustain innovative methods.

\section{References}

Adams J W, Rodriguez D, Cox R A, 2005. The uptake of $\mathrm{SO}_{2}$ on Saharan dust: A flow tube study. Atmospheric Chemistry \& Physics, 5(3): 2643-2676.

Amos P K, Mickley L J, Jacob D J, 2010. Correlations between fine particulate matter $\left(\mathrm{PM}_{2.5}\right)$ and meteorological variables in the United States: Implications for the sensitivity of $\mathrm{PM}_{2.5}$ to climate change. Atmospheric Environment, 44(32): 3976-3984.

Anselin L, 1988. Spatial Econometrics: Methods and Models. Dordrecht: Kluwer Academic Publishers, 10-19.

Anselin L, Kelejian H H, 1997. Testing for spatial error autocorrelation in the presence of endogenous regressors. International Regional Science Review, 20(79): 153-182.

Chameides W L, Li X S, Tang X Y et al., 1999. Is ozone pollution affecting crop yields in China. Geophysical Research Letters, 26(7): 867-870.

Chan C, Yao X, 2008. Air pollution in mega cities in China. Atmospheric Environment, 42(1): 1-42.

Cliff A D, Ord J K, 1982. Spatial processes: Models and applications. Population, 37: 963.

Damodar N. Gujarati, Dawn C. Porter, 2013. Basic Econometrics. 5th ed. Tata McGraw-Hill Education Pvt. Ltd., $310-315$.

Fang Chuanglin, Wang Deli, 2011. Comprehensive measures and improvement of Chinese urbanization development quality. Geographical Research, 30(11): 1931-1946. (in Chinese)

Grossman G M, Krueger A B, 1992. Environmental impacts of North American Free Trade Agreement. Social Science Electronic Publishing, 8(2): 223-250.

Han L J, Zhou W Q, Li W F et al., 2014. Impact of urbanization level on urban air quality: A case of fine particles $\left(\mathrm{PM}_{2.5}\right)$ in Chinese cities. Environmental Pollution, 194(7): 163-170.

Huang Jinchuan, Fang Chuanglin, 2003. Analysis of coupling mechanism and rules between urbanization and eco-environment. Geographical Research, 22(2): 211-220. (in Chinese)

Huang W, Tan J, Kan H et al., 2009. Visibility air quality and daily mortality in Shanghai, China. Sci. Total Environ., 407(10): 3295-3300.

Hyslop N P, 2009. Impaired visibility: The air pollution people see. Atmospheric Environment, 43(1): $182-195$.

Li Wenjie, Zhang Shihuang, Gao Qingxian et al., 2012. Relationship between temporal-spatial distribution pattern of air pollution index and meteorological elements in Beijing, Tianjin and Shijiazhuang. Resources Science, 34(8): 1392-1400. (in Chinese)

Li Xiangyang, Ding Xiaomei, Gao Hong et al., 2011. Characteristics of air pollution index in typical cities of North China. Journal of Arid Land Resources and Environment, 5(3): 96-101. (in Chinese)

Luo C, John J C, Zhou X J et al., 2000. A non-urban ozone air pollution episode over eastern China: Observations and model simulations. Journal of Geophysical Research, 105(D2): 1889-1908.

Ma Limei, Zhang Xiao, 2014. The spatial effect of China's haze pollution and the impact from economic change and energy structure. China Industrial Economics, (4): 19-31. (in Chinese)

Panayotou T, 2001. Demystifying the Environmental Kuznets curve: Turning a black boxintoa policy tool. Environment and Development Economics, 2(4): 465-484.

Patton A P, Perkins J, Zamore W et al., 2014. Spatial and temporal differences in traffic-related air pollution in three urban neighborhoods near an interstate highway. Atmospheric Environment, 99: 309-321.

Peng Jian, Chen Sha, Lü Huiling et al., 2016. Spatiotemporal patterns of remotely sensed $\mathrm{PM}_{2.5}$ concentration in China from 1999 to 2011. Remote Sensing of Environment, 174: 109-121 
Pope C A, Dockery D W, 2006. Health effects of fine particle air pollution: Lines that connect. Journal of the Air \& Waste Management Association, 56(6): 709-742.

Qiao X, Jaffe D, Tang Y et al., 2015 Evaluation of air quality in Chengdu, Sichuan Basin, China: Are China's air quality standards sufficient yet? Environ. Monit. Assess., 187(5): 1-11.

Sarrat C, Lemonsu A, Masson V et al., 2006. Impact of urban heat island on regional atmospheric pollution. Atmospheric Environment, 40(10): 1743-1758.

Tian S, Pan Y, Liu Z et al., 2014. Size-resolved aerosol chemical analysis of extreme haze pollution events during early 2013 in urban Beijing, China. Journal of Hazardous Materials, 279(28): 452-460.

Wang Angyang, Pan Yue, Tong Yanbing, 2015. Research of temporal and spatial distribution of air pollution in the major cities of the Yangtze River Delta. Environmental Protection Science, 41(5): 131-136. (in Chinese)

Wang Dai, Liu Yi, 2016. Spatiotemporal differences and driving forces of air quality in Chinese cities. Journal of Resources and Ecology, 7(2): 1-8.

Wang Haipeng, Zhang Bin, Liu Zuhan et al., 2011. Wavelet analysis of air pollution index changes in Lanzhou during the last decade. Acta Scientiae Circumstantiae, 31(5): 1170-1076. (in Chinese)

Wang S L, Gao J, Zhang Y C et al., 2014. Impact of emission control on regional air quality: An observational study of air pollutants before, during and after the Beijing Olympic Games. Journal of Environmental Sciences, 26(1): 175-180.

Wang S X, Hao J M, 2012. Air quality management in China: Issues, challenges, and option. Journal of Environmental Sciences, 24(1): 2-13.

Wang Shulan, Zhang Yuanhang, Zhong Liujv et al., 2005. Interaction of urban air pollution among cities in Zhujiang Delta. China Environment Science, 25(2): 133-137. (in Chinese)

Wang T, Vincent T F, Cheung M et al., 2001. Ozone and related gaseous pollutants in the boundary layer of eastern China: Overview of the recent measurements at a rural site. Geophysical Research Letters, 28(12): 2373-2376.

Wang Yan, Chai Fahe, Wang Yonghong et al., 2008. Transport characteristics of air pollutants over the Yangtze Delta. Environmental Science, 29(5): 1430-1435. (in Chinese)

Wang Zhenbo, Fang Chuanglin, Xu Guang et al., 2015. Spatial-temporal characteristics of the $\mathrm{PM}_{2.5}$ in $\mathrm{China}$ in 2014. Acta Geographica Sinica, 70(11): 1720-1734. (in Chinese)

Wing I S, 2008. Explaining the declining energy intensity of the US economy. Resource and Energy Economics, 30(1): 21-49.

Wu Ying, Ji Dongsheng, Song Tao et al., 2011. Characteristics of atmospheric pollutants in Beijing, Zhuozhou, Baoding and Shijiazhuang during the period of summer and autumn. Environmental Science, 32(9): 27412749. (in Chinese)

Xi Penghui, Liang Ruobing, 2015. The impact of gasoline price fluctuation on the air pollution: Through the channel of motor vehicle use. China Industrial Economy, (10): 100-114. (in Chinese)

Xu J L, Zhu Y X, Li J L, 1999. Case studies on the processes of surface ozone pollution in Shanghai. Journal of the Air \& Waste Management Association, 49(6): 716-724.

$\mathrm{Xu}$ Xiangde, Zhou Xiuji, Shi Xiaohui et al., 2005. Spatial structure and scale characteristics of air pollution impacts in urban community. Science in China, 35(S1): 1-19. (in Chinese)

Yang Qingke, Duan Xuejun, Zhang Wei et al., 2014. Spatial evolution of high-tech industry development level in China and analysis of the influencing factors. Resources and Environment in the Yangtze Basin, 23(12): 1649-1658. (in Chinese)

Zakey A S, Solmon F, Giorgi F, 2006. Implementation and testing of a desert dust module in a regional climate model. Atmospheric Chemistry \& Physics, 6(2): 4687-4704.

Zhang Renwen, Fan Shaojia, 2011. Study of the influence of wind field on air quality over the Pearl River Delta. Acta Scientiarum Naturalium Universitatis Sunyatseni (Natural Science Edition), 50(6): 130-134. (in Chinese)

Zhao J, Chen S, Wang H et al., 2012. Quantifying the impacts of socio-economic factors on air quality in Chinese cities from 2000 to 2009. Environmental Pollution, 167(6): 148-154.

Zhao X J, Zhang X L, Xu X F et al., 2009. Seasonal and diurnal variations of ambient $\mathrm{PM}_{2.5}$ concentration in urban and rural environments in Beijing. Atmospheric Environment, 43(3): 2893-2900. 